\title{
Atopie: Gene oder Umwelt?
}

\section{Der Fragestellung „Gestiegene Allergieinzidenz - liegt's an den Genen oder der Umwelt?" ging eine schottische}

Zwei-Generationen-Studie nach. Ihr Ergebnis bestätigt: Veränderte Umweltbedingungen leisten ihren Beitrag zum rasanten Anstieg von Allergien, Gene sind aber nicht ganz unbeteiligt.

In der Studie von G. L. Christie und Mitarbeitern der Universität Aberdeen wurden die Daten von zwei Familiengenerationen ausgewertet. $\mathrm{Zu}$ der Gruppe der ersten Generation gehörten 79 Personen, die 1964 an einer Studie zur Prävalenz von Asthma und ,Wheezing" teilnahmen.

\section{Datenvergleich zwischen \\ Eltern und Kindern}

Die Studienteilnehmer der ersten Generation waren ausgewählt worden, weil sie Kinder von Asthmatikern waren. Asthma wurde damals definiert als rezidivierende obstruktive Luftnot ohne erkennbare (infektiöse) Ursache. „Wheezing“ wurde seinerzeit diagnostiziert, wenn die gleichen Symptome im Rahmen einer Erkältung auftraten. Außerdem wurde in der über 30 Jahre alten Studie untersucht, ob die Teilnehmer, die zum Zeitpunkt der Studiendurchführung zwischen 10 bis 15 Jahre alt waren, eine Atopie hatten.

Heute haben die Kinder von damals selber Kinder im Teenageralter. Wenn Asthma erblich ist, dann sollten die Kinder der Atopiker selbst Atopiker sein und auch häufiger an Asthma erkranken als andere Kinder, so die Arbeitshypothese.

Die erste Vermutung traf zu, so die Ergebnisse: Die Kinder von Atopikern hatten signifikant höhere Gesamt-IgESpiegel im Serum als die Kinder von Nicht-Atopikern. Dies war jedoch nicht gleichbedeutend mit einem erhöhten Asthmarisiko. Das Asthmarisiko war nur dann erhöht, wenn die Eltern selbst Asthma hatten. Wenn die Eltern als Atopiker lediglich an
„Wheezing“ litten, war bei den Kindern kein erhöhtes Asthma- oder „Wheezing“-Risiko nachweisbar. Die meisten dieser Kinder waren Atopiker - nachgewiesen durch erhöhte IgEWerte und positiven Pricktest -, aber ansonsten gesund.
Genetik allein erklärt nicht den rasanten Anstieg von Allergien Überraschend war ein deutlicher Anstieg der Atopien bei den Kindern von asymptomatischen Nichtatopikern. Hier lag die Häufigkeit von Asthmaerkrankungen und der Neigung zum „Wheezing“ ebenso hoch wie in der Gruppe der Kinder, welche das Asthma von ihren Eltern geerbt hatten. Jedes zweite Kind hatte „Wheezing“Attacken bei Erkältungen und jedes zweite Kind hatte einen positiven Pricktest.

Auch wenn die geringe Fallzahl der Studie keine weitergehenden Interpretationen zuläßt, ist der dramatische Anstieg der Sensibilisierungen im Verlauf von nur einer Generation doch beeindruckend.

(rme)

Christie GL, et al. Asthma, wheezy bronchitis, and atopy across two generations. Am J Respir Crit Care Med 1999; 159

\section{Atopie durch Adoption}

\section{Adoptierte Kinder übernehmen das Atopierisiko ihrer Adoptiv- eltern, so das Ergebnis einer amerikanischen Pilotstudie.}

Allergien gelten in erster Linie als vererbte Krankheiten. Diese Erkenntnis gründet sich vor allem auf Ergebnisse von Zwillingsstudien.

Einen anderen Ansatz verfolgten Jeanne Smith et al. von der Universität in Iowa City. Sie konnten sich an einer Studie von Psychiatern beteiligen, welche die Auswirkungen der Adoption auf das psychische Wohlbefinden untersuchen wollte. Derartige Adoptivstudien sind schwer durchführbar, weil die Behörden ihre Adressendateien restriktiv handhaben. Deshalb war es auch nicht möglich, die Teilnehmer allergologisch $\mathrm{zu}$ untersuchen. Smith durfte lediglich einen Fragebogen entwerfen, den die Psychiater zusätzlich zu ihren Untersuchungen mit den Adoptivkindern und -eltern ausfüllten.

Untersucht wurden 367 Adoptivkinder, die spätestens im Alter von 3 Monaten von den Adoptiveltern aufgenommen worden waren. Die Adoption lag zum Zeitpunkt der Umfrage bereits 18 bis 45 Jahre zurück.
Die Auswertung ergab, daß adoptierte Kinder mehr als dreimal häufiger an Asthma oder einer allergischen Rhinitis erkranken, wenn die Adoptivmutter an Asthma oder einer allergischen Rhinitis erkrankt war. Das relative Risiko betrug 3,2 bzw. 3,4 und war statistisch hochsignifikant $(\mathrm{n}<$ 0,01 bzw. $\mathrm{n}<0,005$ ). Der Einfluß der Väter war dagegen weitaus geringer und lag unter dem Signifikanzniveau. Information über eine mögliche atopische Veranlagung der natürlichen Eltern waren jedoch nicht verfügbar.

Trotz der hohen Fallzahl dieser Studie lehnen es die Autoren allerdings $\mathrm{ab}$, weitreichende Schlüsse aus ihrer Studie zu ziehen. Dies wird erst dann der Fall sein, wenn die Ergebnisse in weiteren Studien mit vergleichbarer Methodik - und allergologischer Untersuchung von Eltern und Kindern bestätigt werden sollten.

(rme)

Smith JM, et al. Asthma and allergic rhinitis in adoptees and their adoptive parents. Ann Allergy Asthma Immunol 1998; 